\title{
Finescale Assessment of Mobile Home Tornado Vulnerability in the Central and Southeast United States
}

\author{
STEPHEN M. STRADER \\ Department of Geography and the Environment, Villanova University, Villanova, Pennsylvania \\ WALKER S. ASHLEY \\ Department of Geographic and Atmospheric Sciences, Northern Illinois University, De Kalb, Illinois
}

(Manuscript received 4 June 2018, in final form 15 August 2018)

\begin{abstract}
Research has illustrated that tornado disaster potential and impact severity are controlled by hazard risk and underlying physical and social vulnerabilities. Previous vulnerability studies have suggested that an important driver of disaster consequence is the type of housing affected by tornadic winds. This study employs a Monte Carlo tornado simulation tool; mobile home location information derived from finescale, land-parcel data; and census enumerations of socioeconomic vulnerability factors to assess the tornado impact probability for one of the most wind hazard-susceptible demographics in the United States: mobile home residents. Comparative analyses between Alabama and Kansas are employed to highlight regional (i.e., Southeast vs Great Plains) differences in mobile home tornado risk, exposure, and vulnerability. Tornado impact potential on mobile homes is 4.5 times (350\%) greater in Alabama than in Kansas because Alabama, in comparison to Kansas, is represented by 1) a greater number of mobile homes and 2) a more sprawling mobile home distribution. Findings reveal that the Southeast's mobile home residents are one of the most socioeconomically and demographically marginalized populations in the United States and are more susceptible to tornado impact and death than illustrated in prior research. Policy makers, engineers, and members of integrated warning teams (i.e., National Weather Service, media, emergency managers, and first responders) should use these findings to initiate a dialogue and construct interdisciplinary actions aimed at improving societal and individual resilience before, during, and after hazardous weather events.
\end{abstract}

\section{Introduction and background}

On 21-22 January 2017, a Southeast U.S. tornado outbreak produced over 80 tornadoes, $\$ 1.1$ billion in direct losses, and 20 fatalities (NOAA/NCEI 2018). Nearly all the deaths in this event occurred in mobile, or manufactured, housing $(\mathrm{MH}){ }^{1}$ The relationship between tornado fatalities and MH stock in the Southeast is a common theme established in prior research assessing tornado mortality (e.g., Brooks and Doswell 2002; Ashley 2007; Schmidlin et al. 2009; Chaney and

\footnotetext{
${ }^{1}$ Although there are slight differences between mobile and manufactured homes, we follow Sutter and Simmons (2010) in using the more prevalent mobile home term for either those factory built and/or capable of being moved (single or double wide).
}

Corresponding author: Stephen M. Strader, stephen.strader@ villanova.edu
Weaver 2010; Sutter and Simmons 2010; Ash 2017). Many studies have focused on either tornado risk ${ }^{2}$ (Brooks et al. 2003; Dixon et al. 2011; Brooks et al. 2014) or societal vulnerability (Cutter et al. 2003; Ashley 2007; Chaney and Weaver 2010; Sutter and Simmons 2010; Emrich and Cutter 2011; Dixon and Moore 2012; Ash 2017) elements within the context of tornado disasters and associated fatalities. Much of this research has indicated that while hazard risk is vital in creating the potential for tornado disaster, the consequences or

\footnotetext{
${ }^{2}$ In this research, tornado risk is defined as the probability of a tornado of a specific EF magnitude occurring in space and time. We follow Morss et al. (2011), where vulnerability is the susceptibility of people or a system to damage or harm and contains elements of exposure (people, assets, or characteristics of the natural and/or built environment that position a system to be affected by a hazard), sensitivity (degree to which a system is affected by hazard conditions), and adaptive capacity (ability for the system to cope or adapt to hazard conditions).
} 
severity of tornado impacts on populations are controlled largely by the underlying physical and societal vulnerabilities. To date, there has been little research on how tornado risk and $\mathrm{MH}$ resident vulnerability act together at fine spatial scale to create tornado disaster potential in the Southeast.

Research investigating tornado risk has examined spatiotemporal aspects of tornado occurrence (e.g., Brooks et al. 2003; Dixon et al. 2011; Brooks et al. 2014; Ashley and Strader 2016) and/or the interaction of tornadoes with society (e.g., Wurman et al. 2007; Ashley et al. 2014). Studies have also explored mortality trends and found that although tornadoes are most common in the central Great Plains, fatal tornado frequency and mortality rates are much higher in the Southeast (Brooks and Doswell 2002; Ashley 2007; Simmons and Sutter 2011; Ashley and Strader 2016). While the Southeast's elevated tornado death rates have been attributed to many factors (e.g., more frequent nighttime tornadoes and forest cover), a primary contributor to elevated mortality in the Southeast is thought to be the high percentage of MH stock (Ashley 2007). MHs are the circumstance of death for a near majority of all tornado-related fatalities in the region (Brooks and Doswell 2002; Ashley 2007; Sutter and Simmons 2010). The likelihood of a tornado fatality in an MH is 15-20 times greater than in permanent homes $(\mathrm{PH}$; Brooks and Doswell 2002; Sutter and Simmons 2010). Prior research has also suggested that $\mathrm{MHs}$ in the Southeast are not distributed across the landscape evenly and are found most frequently in rural areas (Cutter et al. 2003; Schmidlin et al. 2009; Emrich and Cutter 2011). This more spatially dispersed development character may lead to increased odds of tornado impact (Strader et al. 2018) and enhanced vulnerability due to lack of resource access, limited social and political networks, and density of infrastructure that provide lifelines during emergency situations (Cutter et al. 2003).

Studies have also examined both physical and social vulnerability components for MH residents and tornado hazards (e.g., Merrell et al. 2002; Ashley 2007; Simmons and Sutter 2007, 2008; Schmidlin et al. 2009; Sutter and Simmons 2010; Ash 2017). Physical vulnerability factors associated with MHs often refer to the age of the structure, construction quality, and lack of proper stormsheltering options (Simmons and Sutter 2008; Schmidlin et al. 2009). Social vulnerability is regularly directed at economic and demographic characteristics (e.g., poverty, gender, race, age, and education) of a population (Cutter et al. 2003; Emrich and Cutter 2011). Ultimately, research assessing tornado risk and vulnerability for MH populations has often concentrated efforts at large spatial scales, such as county or state levels (e.g., Boruff et al. 2003; Sutter and Simmons 2010). A small number of studies have examined subcounty-level tornado $\mathrm{MH}$ vulnerability, but only for small areas (e.g., Schmidlin et al. 2009; Chaney and Weaver 2010; Ash 2017). As such, there has been no research to date that has attempted to connect tornado vulnerability to the household scale for a large region, especially one plagued by high tornado casualty rates. Because most studies have used county-level enumerations of $\mathrm{MH}$ counts and vulnerability factors, the overall understanding of how social and physical vulnerabilities, as well as capacities, manifest at the MH-unit scale during tornado hazard situations has been constrained. Our study, including a rich resource of highresolution quantitative geospatial data, confronts the limited understanding of the $\mathrm{MH}$ tornado problem in the Southeast.

The primary objective of this study is to examine $\mathrm{MH}$ vulnerability and tornado risk at a fine spatial scale for the Southeast and central Plains. We investigate how the spatial character of MHs and resident vulnerability varies across geographic space and shapes disaster consequences. This study moves beyond understanding how MH counts and vulnerability constituents at the county scale influence tornado disaster potential by examining vulnerability at the census block group and land-parcel, or individual property, levels. This finescale assessment provides a more precise appraisal of $\mathrm{MH}$ tornado risk and vulnerability with the goal of promoting a deeper understanding of how $\mathrm{MH}$ vulnerability and tornado risk interact to create disaster.

\section{Methods}

The analyses conducted in this study focus on the states of Kansas and Alabama. These two states were selected because they are representative of distinct tornado risk and vulnerability regions in the United States. Alabama is in the heart of the Southeast, where tornado [category 1 and higher on the enhanced Fujita scale $(\mathrm{EF} 1+)]$ occurrence is high and tornado mortality rates are greater than any other location in the United States (Brooks and Doswell 2002; Ashley 2007; Ashley et al. 2008; Simmons and Sutter 2011; Ashley and Strader 2016). Kansas was selected for comparison to Alabama because it is situated in a region of the United States that also experiences many tornadoes annually, in what has been colloquially termed "Tornado Alley" (Brooks et al. 2003; Ashley 2007; Gagan et al. 2010; Dixon et al. 2011; Dixon and Mercer 2012; Ashley and Strader 2016). However, Kansas has a relatively lower tornado mortality rate, compared to Alabama (Ashley 2007; Ashley and Strader 2016). Because both states 
have similar tornado risk (Ashley and Strader 2016), the disparity between Alabama and Kansas tornado mortality may be attributed to the differences between the central Plains' and Southeast's underlying land-use patterns, socioeconomic and demographic ${ }^{3}$ vulnerabilities, and built-environment characteristics (Ashley 2007; Simmons and Sutter 2011; Ashley and Strader 2016; Strader et al. 2016).

We first update and support prior work by examining U.S. tornado risk and mortality using spatial and statistical techniques. An emphasis is placed on fatal tornado occurrence, circumstance, and location (i.e., $\mathrm{MH}$ or PH and latitude-longitude). Thereafter, the finescale $\mathrm{MH}$ location data derived from land-parcel data are employed to determine the current spatial patterns of MH counts and associated variability across Alabama and Kansas. Although the acquired raw character landparcel data captured most MH locations for Kansas and Alabama, many $\mathrm{MH}$ records were absent from the landparcel dataset. To account for missing MHs, aerial imagery from the Environmental Systems Research Institute (ESRI) was used to digitize the missing $\mathrm{MH}$ locations within the states. Specifically, 1-m or better areal imagery used was derived from a variety of satellite imagery sources, including the National Agriculture Imagery Program (NAIP) and the ESRI Community Maps Program. A "heads up" digitization method was employed by zooming in on the aerial imagery and subsequently employing Google's Street View to confirm if a building was indeed an MH. Because MHs are prefabricated, the typical size (i.e., $5.5 \mathrm{~m} \times 27 \mathrm{~m}$ for single wide and $6.1 \mathrm{~m} \times 27 \mathrm{~m}$ ) was also used to distinguish MHs from other buildings or structures. In general, this manual data-gathering process ensured that a complete-as-possible record of $\mathrm{MH}$ locations was generated for each state. This methodology assured that given a $100-\mathrm{km}^{2}$ region in Alabama or Kansas, $\mathrm{MH}$ counts were within $12 \%$ of the actual number of $\mathrm{MHs}$ in the regions. For example, if there were 100 actual MHs in a $100-\mathrm{km}^{2}$ region, the parcel and digitized supplemental data-gathering process captured at least $88 \mathrm{MHs}$. This finescale spatial accuracy makes the $\mathrm{MH}$ data employed in this study the most accurate and precise collection of MH locations for these states. Following the $\mathrm{MH}$ data-gathering process, a geographic information system (GIS) was used to calculate spatial statistics, such

\footnotetext{
${ }^{3}$ In this study, we define socioeconomic status as a measure of a person's combined economic and social standing (Baker 2014). Factors such as education, income, and occupation are utilized to determine the socioeconomic character of a population. We also follow Morrill (1990), who uses metrics such as age and race to describe the demographic character of a population.
}

as Ripley's $K$ function (RKF) analyses, on MHs in the two states (Dixon 2002). RKF is a multidistance spatial cluster analysis method that determines if there is clustering or dispersion of geographic points and measures the degree of clustering or dispersion over a range of search distances.

The study also uses census block group enumerations and land-use data in conjunction with GIS techniques, such as zonal statistics, to determine the locational, socioeconomic, and demographic settings of MHs within Kansas and Alabama. We use the 2012-16 American Community Survey (ACS) block group data enumerations such as total population, race, gender, age, educational attainment, household income, poverty relative to the poverty level, and public assistance as measures of demographic and socioeconomic vulnerability (Cutter et al. 2003, 2009; Emrich and Cutter 2011). Using these socioeconomic and demographic measures, we created the socioeconomic and demographic vulnerability index (SEDVI). Specifically, census block group enumerations of socioeconomic and demographic data (i.e., race, sex, age, income, public assistance, education, and household status) from the 2012-16 ACS were gathered for Alabama and Kansas (Table 1). Block group totals of these socioeconomic and demographic measurements were converted into a percentage of total population or households within that block group. For example, the sum number of female persons within a block group was converted to the percentage of the total population that is female. This process was repeated for all SEDVI variables. Each of these socioeconomic and demographic variable percentage calculations (Var) was then weighted equally and summed to provide a census block group SEDVI score [Eq. (1)], or

$$
\operatorname{SEDVI}=\sum_{i=1}^{n} \operatorname{Var}_{i}=\operatorname{Var}_{1}\left(\frac{1}{n}\right)+\cdots+\operatorname{Var}_{n}\left(\frac{1}{n}\right) .
$$

The SEDVI and associated vulnerability metrics were then mapped and examined to better understand the socioeconomic and demographic settings of MHs. Landuse and housing unit (HU) estimations from the Spatially Explicit Regional Growth Model (SERGoM) are also employed to determine whether MHs and all HUs are situated in rural ( $>16.18$ ha per home), exurban (0.68-16.18 ha per home), suburban (0.1-0.68 ha per home), and urban $(<0.1$ ha per home) land-use classifications (Theobald 2005).

We also investigate the physical exposure component of $\mathrm{MH}$ vulnerability by using historical tornado paths and land-parcel-level MH data within a Monte Carlo modeling framework. The Tornado Impact Monte Carlo (TorMC) model has been developed, tested, and 
TABLE 1. Socioeconomic and demographic variable descriptions and concepts used to create the SEDVI. Vulnerability metrics and variables are based on prior hazards vulnerability work outlined by Cutter et al. (2003, 2009).

\begin{tabular}{|c|c|c|}
\hline Factor & $\begin{array}{l}\text { Variable (percentage of population } \\
\text { or households) }\end{array}$ & Effect on vulnerability \\
\hline \multirow[t]{2}{*}{ Race } & Black & $\begin{array}{l}\text { Cultural barriers (Peacock et al. 1997; Cutter et al. 2006; } \\
\text { Elder et al. 2007) }\end{array}$ \\
\hline & Hispanic & $\begin{array}{l}\text { Cultural and language barriers (Peguero 2006; } \\
\text { Trujillo-Pagan 2007) }\end{array}$ \\
\hline Sex & Female & $\begin{array}{l}\text { Employment types; lower wages; family care responsibility } \\
\text { (Enarson et al. 2007) }\end{array}$ \\
\hline Age & $\begin{array}{l}\text { Less than } 5 \text { years old } \\
\text { Less than } 18 \text { years old (minor) } \\
\text { More than } 65 \text { years old }\end{array}$ & $\begin{array}{l}\text { Mobility; dependence on others (Phillips and Hewett 2005; } \\
\text { Smith et al. 2009) }\end{array}$ \\
\hline Income & $\begin{array}{l}\text { In poverty in last } 12 \text { months } \\
\text { Unemployed or not in work force } \\
\text { in last } 12 \text { months }\end{array}$ & $\begin{array}{l}\text { Lower ability to absorb and losses; lower resilience; fewer } \\
\text { financial and social safety nets (Peacock et al. 1997; } \\
\text { Fothergill and Peek 2004; Masozera et al. 2007) }\end{array}$ \\
\hline Public assistance & $\begin{array}{l}\text { With public assistance in last } 12 \text { months } \\
\text { On food stamps in last } 12 \text { months } \\
\text { With disability in last } 12 \text { months }\end{array}$ & $\begin{array}{l}\text { Unable to respond to hazards effectively due to already } \\
\text { being economically and socially disadvantaged (McGuire et al. } \\
\text { 2007; Morrow 2008) }\end{array}$ \\
\hline Education & $\begin{array}{l}\text { Less than high school education } \\
\text { (less than ninth grade) }\end{array}$ & $\begin{array}{l}\text { Relationship to income and economic constraints; } \\
\text { understanding of warning and recovery information } \\
\text { (Mitchell et al. 2000) }\end{array}$ \\
\hline Household & $\begin{array}{l}\text { Single female head of house } \\
\text { Household size greater than four people } \\
\text { Renters }\end{array}$ & $\begin{array}{l}\text { Limited financial resources; economic, social, and family } \\
\text { responsibilities (Morrow 1999; Cutter et al. 2009) }\end{array}$ \\
\hline
\end{tabular}

demonstrated in prior research (e.g., Strader et al. 2016, 2017a,b). Monte Carlo simulation is a modeling technique that uses repeated random sampling to obtain the distribution of an unknown probabilistic entity (Mooney 1997). Monte Carlo methods have previously been used to investigate risk and tornado climatology (Meyer et al. 2002), potential impacts on policy holders (Daneshvaran and Morden 2007), and tornado disaster or impact likelihood on the built environment (Strader et al. 2016, 2017a,b). Specific TorMC methods, components, and modeling options are discussed in Strader et al. (2016).

For this study, 10000 years of EF1+ tornado footprints (i.e., pathlength by path width; representative maximum extent of tornadic winds in a tornado event) were simulated across Alabama and Kansas. A 10000 -yr simulation length was selected because it produced functional, yet computationally and temporally efficient, output for both Alabama and Kansas. EF1+ tornadoes were simulated since they have been historically associated with the greatest number of tornado fatalities, and their annual counts have been relatively stable throughout the period of record (Verbout et al. 2006; Brooks et al. 2003; Ashley 2007; Doswell 2007; Simmons and Sutter 2011; Agee and Childs 2014; Ashley and Strader 2016). Simulated tornado pathlength, width, azimuth, intensity, and frequency were determined by historical tornado data trends using a bootstrap, random selection with replacement method and an underlying spatial weighting process derived from historical tornado risk within Alabama and Kansas (Strader et al. 2016). Tornado impact magnitudes using the TorMC were calculated using a spatial join technique with the simulated tornado paths and the point $\mathrm{MH}$ locations. Results from the TorMC simulations yield tornadoMH impact likelihood and magnitude using descriptive statistics and annual tornado-housing impact probability of exceedance (POE) curves. The MH impact results were compared against HU enumerations. This comparative analysis revealed the relative effects $\mathrm{MH}$ housing stock have on tornado impact potential compared to all housing stock. Ultimately, this portion of the research provides a probabilistic expectation of tornadoMH impact magnitude for each location scenario to illustrate how both the magnitude and spatial distribution of MHs in the Southeast uniquely influence tornado disaster potential.

\section{Results and discussion}

\section{a. Tornado fatalities and housing relationship}

From 1880 to 2017, there have been a total of 19907 tornado fatalities in the contiguous United States. The Southeast states of Alabama, Georgia, Mississippi, and Tennessee had $27 \%$ of all fatalities during this $137-y r$ period, while the central Plains states of Kansas, Nebraska, Oklahoma, and Texas had $21.4 \%$. However, reporting the 


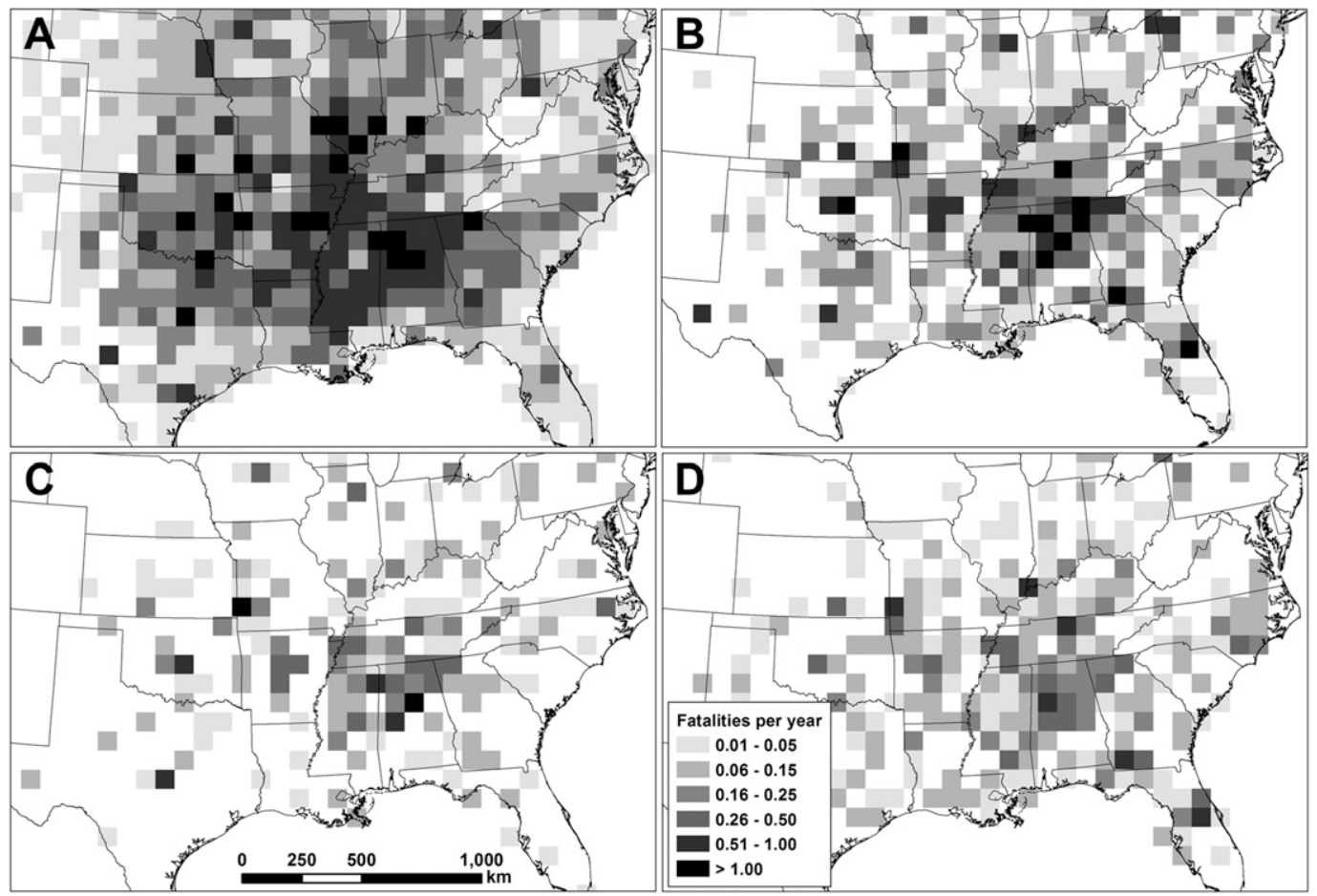

FIG. 1. Tornado fatalities per year in an $80 \mathrm{~km} \times 80 \mathrm{~km}$ grid for (a) 1880-2017, (b) 1985-2017, (c) PH circumstance of death 1985-2017, and (d) MH circumstance of death 1985-2017.

circumstance of tornado death (i.e., $\mathrm{PH}, \mathrm{MH}$, vehicle, outside, etc.) did not become consistent until the mid-1980s (Ashley 2007). From 1985 to 2017, there were 2248 tornado-related fatalities, or 68 fatalities per year in the United States for all circumstances. During the same 33-yr period, there were $731 \mathrm{PH}$ and $872 \mathrm{MH}$ fatalities in the contiguous United States. Together, $\mathrm{PH}$ - and $\mathrm{MH}$-affiliated fatalities made up $72 \%$ of all tornado fatalities since 1985 , with $39 \%$ of all fatalities occurring in MHs. Although MHs represent around $6 \%$ of the entire U.S. housing stock (Gryn 2016), 54\% of all housing-related tornado deaths from 1985 to 2017 occurred in MH structures.

Of the 15 grid cells that resulted in greater than 0.35 MH tornado fatalities per year from 1985 to 2017, 9 were in the Southeast states of Alabama, Georgia, Mississippi, and Tennessee (Fig. 1). In this four-state region, there were a total of 867 tornado deaths, or a mean of 26 fatalities per year from 1985 to 2017. For this same period, 355 fatalities occurred in MHs in the region, or $41 \%$ of all deaths; if the 27 April 2011 outbreak is not considered (which contained many PH deaths), then this percentage would soar to $52 \%$. Comparatively, the central Plains states of Kansas, Nebraska, Oklahoma, and Texas had 351 fatalities since 1985, or a mean of 10 fatalities per year. The central Plains states also had 109 MH fatalities, or approximately, on average, three MH fatalities per year. These results illustrate the linkage between tornado fatalities and housing type. Specifically, tornado fatalities tend to occur in the Southeast, where MH exposure is high (Fig. 2). As discussed in prior studies (e.g., Brooks and Doswell 2002; Ashley 2007), the MH prevalence in the Southeast continues to influence vulnerability to tornadoes and increase the odds of death and injury.

\section{b. Patterns in mobile home location and density}

To explore differences in the relationship among land use, MHs, and tornadoes in the Southeast and central Plains, Alabama and Kansas are used as exemplars of each region. Alabama and Kansas represent distinct combinations of tornado risk and land-use morphologies. Although both states largely comprise low-density land use, rural land in Kansas is nearly $91 \%$ of the total developable land area compared to $68 \%$ in Alabama (Table 2). The primary difference between Alabama and Kansas land use is in the exurban category. While only $8.3 \%$ of Kansas is considered exurban, more than $30 \%$ of all Alabama development is exurban and relatively higher-density rural land use. Kansas was divided into eastern and western regions, since western Kansas is represented by many smaller development centers, or cities, compared to the eastern portion of the state. Because eastern Kansas contains a higher frequency of higher-density urban areas, such as Wichita and 


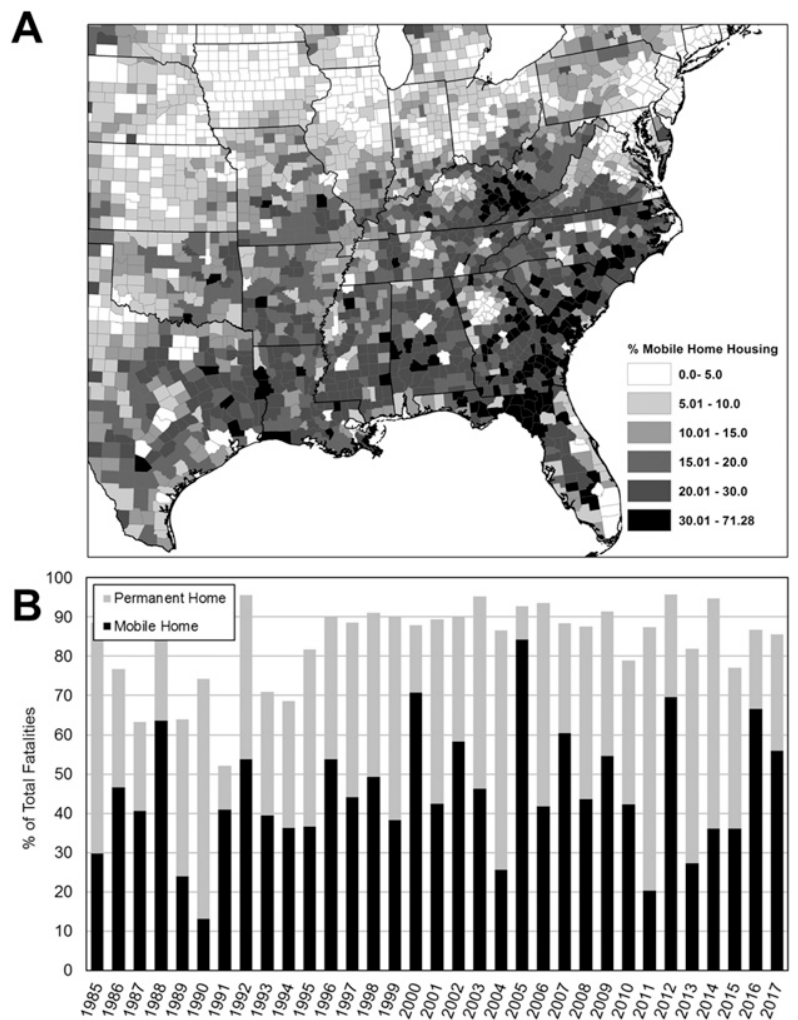

FIG. 2. (a) The percentage of total housing stock that is MH by county 2016 (ACS 2017) and (b) the housing-related percentage of all tornado fatalities from 1985 to 2017.

Kansas City, a greater amount of urban and suburban land use exists in this region. Consequently, development and urban sprawl (Duany et al. 2000; Gillham 2002) are more evident in eastern Kansas compared to western portion of the state. For similar reasons, Alabama was divided into northern and southern regions of development. Housing density and development in Alabama is concentrated north of the East Gulf Coastal Plain region (Fig. 3). This region is also characterized by a high percentage of suburban and exurban land use. Southern Alabama comprises mostly rural land use, except for a high percentage of suburban and urban land use associated with coastal development in Mobile and Baldwin Counties. Research related to tornado disasters and housing density revealed that urban sprawl increases tornado impact and disaster potential, or the so-called expanding bull's-eye effect (Ashley et al. 2014; Strader and Ashley 2015). However, these studies have not specifically examined the contribution of MH stock to this effect.

$\mathrm{MH}$ counts and their distribution across geographies are vastly different between Alabama and Kansas (Table 3, Fig. 3). MH density in Alabama (1.52 MH per km) is much higher than Kansas ( $0.27 \mathrm{MH}$ per km). However, the mean number of MHs in each 2.5-km grid cell for Alabama and Kansas is similar (Table 3). These comparable means can be described, in part, by the variability and difference between Alabama and Kansas MH counts per grid cell. These results suggest that although there are a greater number of MHs in Alabama, MHs in Kansas tend to be in close proximity to other MHs, such as in a community or park. While MHs in Alabama are correspondingly found near each other, they are also more frequently located in lower-density exurban and rural areas. The absence of MHs in exurban and rural locations in Kansas reveals the importance of assessing not only $\mathrm{MH}$ counts, but also the spatial distribution of MHs across the landscape.

RKF results for the entire states of Alabama and Kansas reveal that MH locations in both states are clustered (Fig. 4). In general, this finding was expected because housing and development are clustered across the geographic landscape (Kim 1999; Lang 2003; Greene and Pick 2011; Whyte 2013). However, MH locations in Kansas are $143 \%$ (mean) more clustered than in Alabama. The greatest difference between Alabama and Kansas MH clustering occurs with a search radius of less than $2 \mathrm{~km}$, suggesting that MHs in Kansas are typically found much closer to other MHs, compared to those

TABLE 2. MH counts, HU, percentage of MHs by land use, percentage of HU by land use, and percentage of developable state land area by rural ( $<0.062 \mathrm{HU}$ per ha), exurban $(0.062-1.236 \mathrm{HU}$ per ha), suburban (1.237-9.884 HU per ha), and urban ( $>9.884 \mathrm{HU}$ per ha) land-use classification.

\begin{tabular}{|c|c|c|c|c|c|}
\hline & MH count & Percentage of total MH & Total HU count & Percentage of total HU & Percentage of state land use \\
\hline \multicolumn{6}{|l|}{$\mathrm{AL}$} \\
\hline Rural & 40422 & 20.4 & 156305 & 6.9 & 68.1 \\
\hline Exurban & 116807 & 58.8 & 815709 & 36.0 & 29.8 \\
\hline Suburban & 36473 & 18.4 & 789996 & 34.8 & 1.9 \\
\hline Urban & 4857 & 2.4 & 505153 & 22.3 & 0.23 \\
\hline \multicolumn{6}{|l|}{ KS } \\
\hline Rural & 6300 & 11.7 & 129785 & 8.3 & 90.9 \\
\hline Exurban & 12293 & 22.7 & 276990 & 17.7 & 8.3 \\
\hline Suburban & 25165 & 46.5 & 516218 & 32.9 & 0.59 \\
\hline Urban & 10310 & 19.1 & 646206 & 41.2 & 0.18 \\
\hline
\end{tabular}



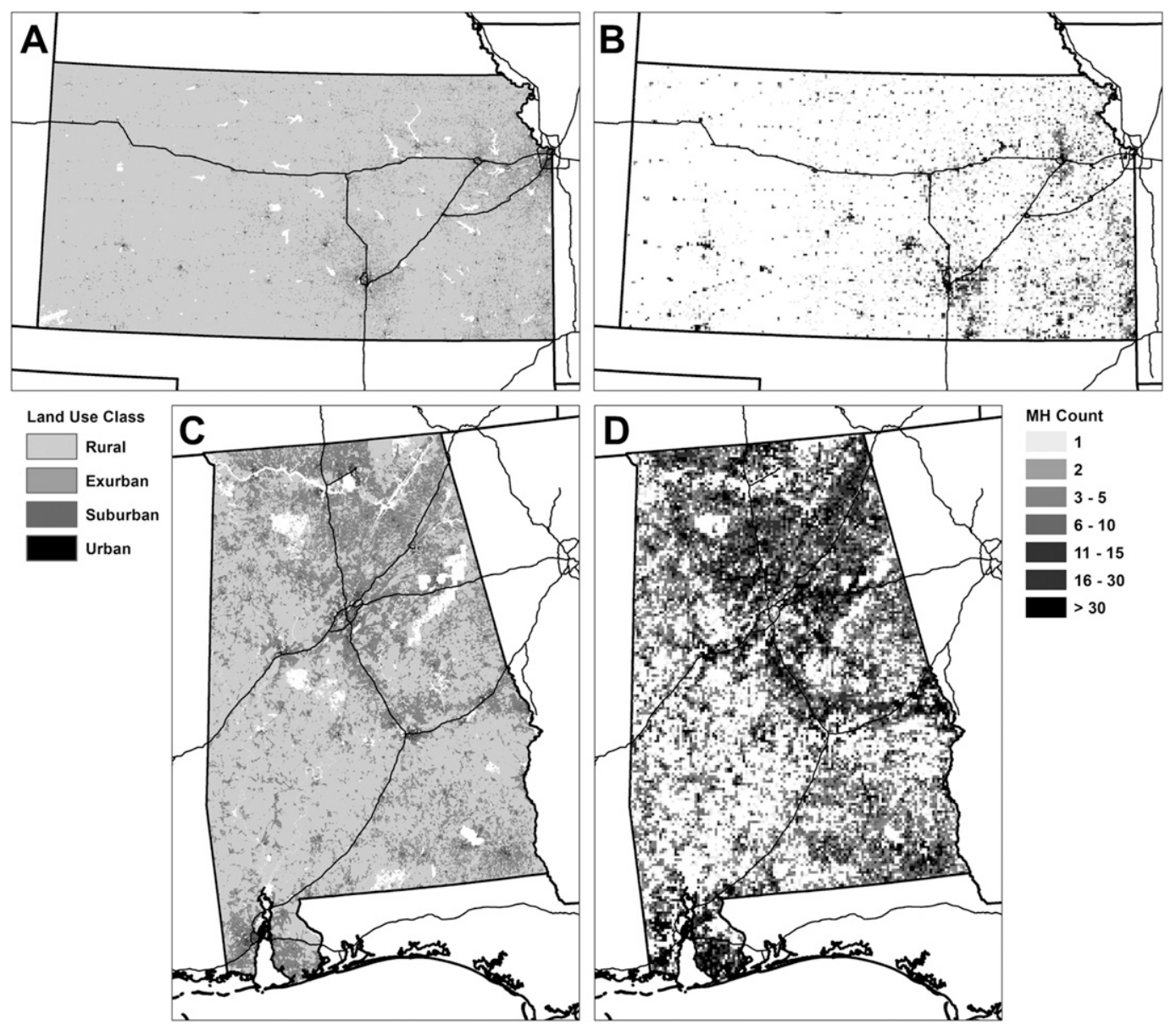

FIG. 3. Land-use classification for (a),(c) all housing and (b),(d) $\mathrm{MH}$ density on a $2.5 \mathrm{~km} \times 2.5 \mathrm{~km}$ grid for (a),(b) KS and (c),(d) AL. Land use categorized as rural (<0.062 HU per ha), exurban (0.062-1.236 HU per ha), suburban (1.237-9.884 HU per ha), and urban ( $>9.884$ HU per ha).

MHs within Alabama. The inverse relationship occurs above a search radius of $2 \mathrm{~km}$, signifying that beyond $2 \mathrm{~km}, \mathrm{MH}$ locations in Kansas are increasingly more dispersed. The more concentrated development patterns and less sprawling land use in Kansas is due to the presence of agricultural and livestock lands (Brown et al. 2005; Kansas Department of Agriculture 2016). This type of land use and zoning restricts development associated with urban centers to sprawl across the landscape. For example, the total percentage of land area that is cropland, pasture, or rangeland in Kansas is $88 \%$, compared to $18 \%$ in Alabama (USDA 2017). As such, because development and urban sprawl is much more restricted in Kansas, MHs are far less likely to be found in rural and exurban locations compared to Alabama.

In Alabama, $58.8 \%$ of all MHs are in exurban landuse density, followed by rural at $20.4 \%$ (Table 1 ). Conversely, the total number of Kansas MHs found in urban areas is $207 \%$ greater than in Alabama, and $65.6 \%$ of Kansas MHs are in suburban and urban densities. The relationship between $\mathrm{MH}$ locations and land use follow

TABLE 3. AL and KS MH statistics. Mean, standard deviation, coefficient of variation, and maximum MH counts were determined within a $2.5 \mathrm{~km} \times 2.5 \mathrm{~km}$ grid across each state.

\begin{tabular}{lcccccc}
\hline \hline & $\begin{array}{c}\text { State } \mathrm{MH} \\
\text { count }\end{array}$ & $\begin{array}{c}\text { State } \mathrm{MH} \\
\text { density }\left(\mathrm{km}^{2}\right)\end{array}$ & $\begin{array}{c}\text { MH count per grid } \\
\text { cell (mean) }\end{array}$ & $\begin{array}{c}\text { MH count per grid } \\
\text { cell (std dev) }\end{array}$ & $\begin{array}{c}\text { MH count per grid cell } \\
\text { (coefficient of variation) }\end{array}$ & $\begin{array}{c}\text { MH count in grid cell } \\
\text { (maximum) }\end{array}$ \\
\hline $\mathrm{AL}$ & 202705 & 1.52 & 9.46 & 25.0 & 2.6 & 1650 \\
$\mathrm{KS}$ & 57298 & 0.27 & 9.27 & 42.3 & 4.6 & 1319 \\
\hline
\end{tabular}


A

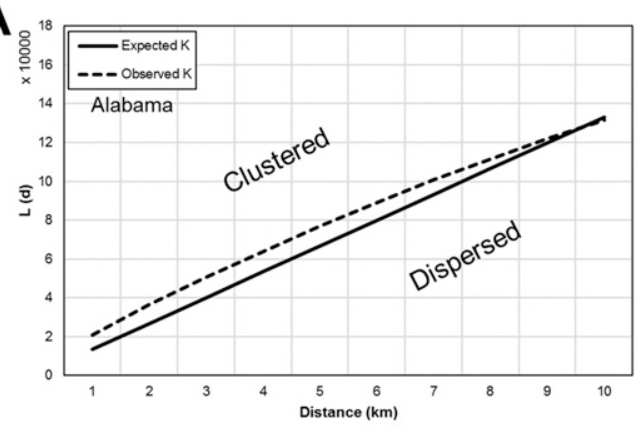

C

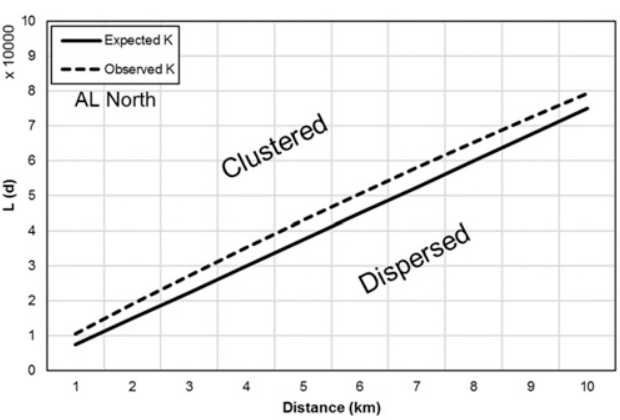

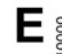

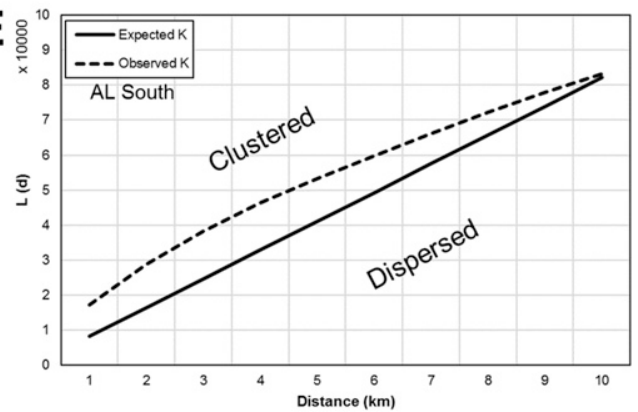

B

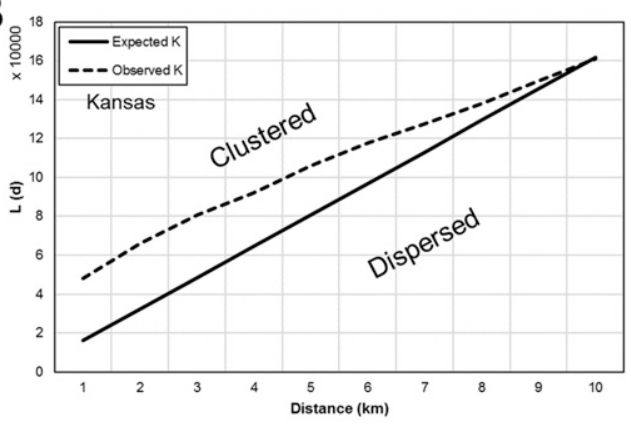

D

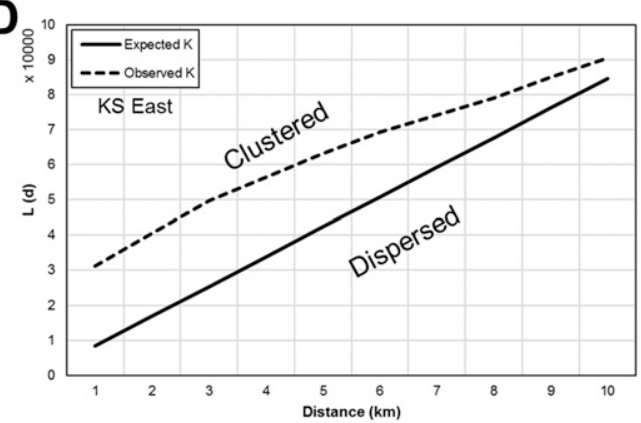

$F_{\text {sू }}$

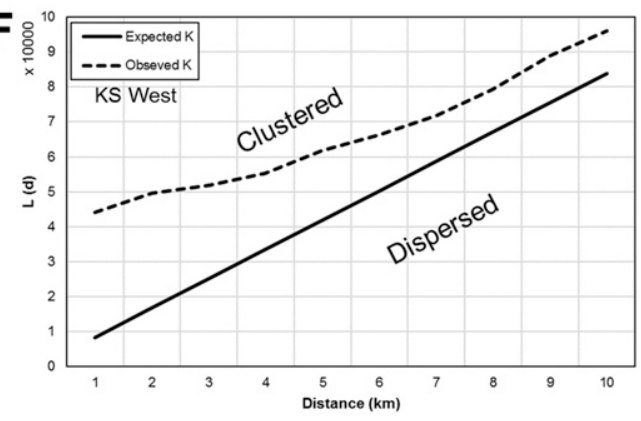

FIG. 4. RKF analyses for (a) AL, (b) KS, (c) northern AL, (d) eastern KS, (e) southern AL, and (f) western KS. Observed $K$ values above (below) the expected $K$ values indicate clustering (dispersion) of MH at search distance of $1-10 \mathrm{~km}$.

similar patterns to HUs in each state (Fig. 3). Alabama MHs are $22.8 \%$ more likely to be found in exurban regions, compared to all housing types. Conversely, it is more likely for Kansas MHs to exist within suburban rather than rural areas. Kansas cities such as Garden City, Dodge City, Colby, Hays, and Liberal exhibit MH location patterns where MHs tend to occur on the periphery of the primary development core (Fig. 4f). Overall, these results indicate that Alabama MHs are more likely to be dispersed across the landscape and found in less dense development compared to Kansas.

\section{c. Alabama and Kansas socioeconomic and demographic vulnerability}

Alabama is more socioeconomically and demographically vulnerable to tornadoes than Kansas (Table 4).
The largest difference between Alabama and Kansas vulnerability metrics is associated with a higher $(17.5 \%)$ percentage of total population that is black in Alabama compared to Kansas. Additionally, the higher percentage of minority (black combined with Hispanic) population in Alabama leads to greater cultural barriers and enhanced vulnerability in hazards situations (Peacock et al. 1997; Cutter et al. 2006; Elder et al. 2007; Cutter et al. 2009). Kansas has a slightly higher $(+0.9 \%)$ mean block group percentage of children under 5 years old, a larger minor population $(+2.1 \%)$, and a lower $(1.2 \%)$ percentage of persons over the age of 65 , indicating that the distribution of population by age in Alabama is skewed toward older populations compared to Kansas. For poverty, unemployment, public assistance, food stamps, disability, single female head of household, and renter 
TABLE 4. Mean, median, and standard deviation of the percentage of population or households within census block groups for AL and KS in specific socioeconomic and demographic metrics that relate to elevated tornado hazard vulnerability. The mean, median, standard deviation, and coefficient of variation for AL and KS block group SEDVI calculations are also presented.

\begin{tabular}{|c|c|c|c|c|c|c|c|c|}
\hline \multirow[b]{2}{*}{ Variable } & \multicolumn{2}{|c|}{ Mean } & \multicolumn{2}{|c|}{ Median } & \multicolumn{2}{|c|}{ Std dev } & \multicolumn{2}{|c|}{$\begin{array}{c}\text { Coefficient of } \\
\text { variation }\end{array}$} \\
\hline & $\mathrm{AL}$ & KS & $\mathrm{AL}$ & KS & $\mathrm{AL}$ & KS & $\mathrm{AL}$ & KS \\
\hline Black & 31.0 & 5.9 & 18.2 & 1.2 & 32.4 & 12.0 & 1.0 & 2.0 \\
\hline Hispanic & 3.7 & 11.6 & 0.9 & 5.5 & 7.2 & 15.7 & 1.9 & 1.4 \\
\hline Female & 51.7 & 50.0 & 51.7 & 50.4 & 6.9 & 6.9 & 0.1 & 0.1 \\
\hline$<5$ years old & 5.8 & 6.7 & 5.2 & 6.2 & 4.1 & 4.2 & 0.7 & 0.6 \\
\hline$<18$ years old & 21.9 & 24.0 & 21.9 & 24.1 & 8.2 & 8.4 & 0.4 & 0.4 \\
\hline$>65$ years old & 16.5 & 15.3 & 15.7 & 14.5 & 8.1 & 8.3 & 0.5 & 0.5 \\
\hline Poverty & 20.2 & 14.1 & 17.0 & 10.2 & 15.1 & 13.1 & 0.7 & 0.9 \\
\hline Unemployed & 48.6 & 37.4 & 48.2 & 37.1 & 12.5 & 11.0 & 0.3 & 0.3 \\
\hline Public assistance & 1.9 & 2.1 & 0.3 & 0.7 & 3.4 & 3.4 & 1.8 & 1.6 \\
\hline Food stamps & 17.9 & 10.2 & 14.8 & 7.2 & 14.4 & 10.7 & 0.8 & 1.0 \\
\hline Disability & 8.4 & 4.3 & 6.5 & 3.1 & 8.1 & 6.2 & 1.0 & 1.4 \\
\hline Less than high school education & 5.5 & 4.3 & 4.2 & 2.1 & 5.3 & 6.3 & 1.0 & 1.5 \\
\hline Single female head of household & 16.2 & 10.4 & 13.5 & 8.4 & 11.9 & 8.5 & 0.7 & 0.8 \\
\hline Household size greater than four people & 27.8 & 31.7 & 27.6 & 30.6 & 12.7 & 14.3 & 0.5 & 0.5 \\
\hline Renters & 15.6 & 14.3 & 14.0 & 12.9 & 9.6 & 8.6 & 0.6 & 0.6 \\
\hline SEDVI & 24.7 & 20.9 & 24.0 & 19.6 & 7.1 & 6.8 & 0.3 & 0.3 \\
\hline
\end{tabular}

vulnerability metrics, the percentages of persons and household are all greater in Alabama than in Kansas.

In general, the largest differences between socioeconomic and demographic variables in Alabama and Kansas are found in the race, income, and public assistance categories. Mean and median SEDVI values for Alabama are considerably higher than Kansas due to the combined higher percentage of vulnerable populations. This result supports prior hazard vulnerability research that suggests enhanced vulnerability to hazards in the Southeast (Dixon et al. 2011; Flanagan et al. 2011; Cutter 2012). However, it is also important to understand where socioeconomically and demographically vulnerable populations overlap within each state.

\section{d. Intrastate socioeconomic and demographic vulnerability patterns}

In addition to the Alabama and Kansas statewide differences in socioeconomic and demographic vulnerability factors, there are also unique spatial patterns of vulnerability within Alabama and Kansas. In Alabama (Fig. 5), high percentages of persons that are black, unemployed, in poverty, on disability, on food stamps, or single females that are the head of their household are often collocated or found in similar regions. Alabama is exemplar of a region with great racial divide across the state that results in enhanced vulnerability to hazards due to increased cultural differences and socioeconomic marginalization (Emrich and Cutter 2011; Cutter 2012). Elevated SEDVI values capture the higher percentages of persons and households that are black, unemployed, in poverty, on disability, on food stamps, or single females that are the head of their household along the East Gulf Coastal Plain region (Fig. 5).

In Kansas, there is less clustering among vulnerability factors than in Alabama. However, slight clustering in SEDVI metrics does occur near urban centers and in the southwest portion of the state, where larger percentages of Hispanic populations reside (Fig. 6). The relatively high percentage of population that is Hispanic in southwestern Kansas is driven by food processing and agriculture that creates employment opportunities for minority populations (Kulcsàr 2007). Much of this same southwestern region of Kansas has percentages of the population with less than a high school education, that is under 18 years old, and with a household size greater than four persons. Because many urban centers in Kansas contain elevated percentages of populations and households that are in poverty, rely on public assistance, and/or are unemployed, SEDVI values tend to be greater on the fringes of these central business districts. Nevertheless, patterns of socioeconomic and demographic vulnerability metrics within Kansas are much less apparent than in Alabama.

\section{e. Linking mobile home locations and socioeconomic and demographic vulnerability}

Comparing spatial measures of MH density, MH landuse settings, and SEDVI-derived vulnerability factors, $\mathrm{MH}$ residents in rural or exurban areas tend to be more socioeconomically and demographically vulnerable to tornadoes, especially in the Southeast. Although the East Gulf Coastal Plains region in Alabama has a lower 

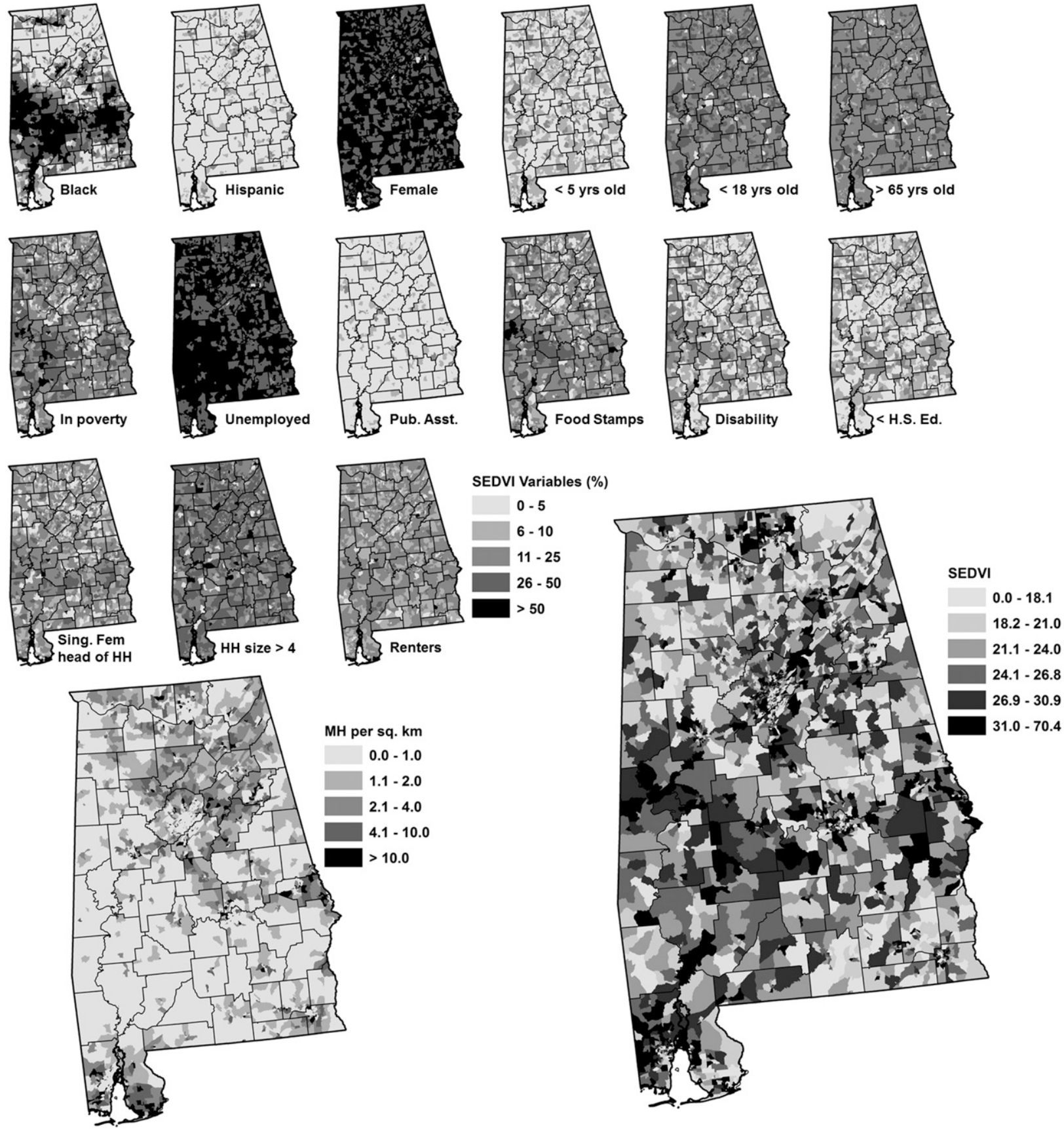

FIG. 5. SEDVI variables, MH density $\left(\mathrm{km}^{2}\right)$, and SEDVI values for $\mathrm{AL}$ within census block group estimates (cf. Tables 1 and 4).

MH density, the percentage of total housing stock in this region that is MHs is greater than any other portion of Alabama. In addition, the East Gulf Coastal Plains region contains a greater amount of rural land use and a higher percentage of vulnerable populations that are black, unemployed, in poverty, on public assistance, or single female head of households. Although this research cannot determine that a single household is both socially and physically vulnerable, the juxtaposition of these measures suggests enhanced social and physical vulnerability to tornadoes within this region of Alabama (Fig. 5). This finding not only supports prior work indicating that MHs tend to be located in greater concentrations within rural and exurban land (Cutter et al. 2003; Schmidlin et al. 2009; Emrich and Cutter 2011), but also demonstrates that MHs, rural/exurban land use, 

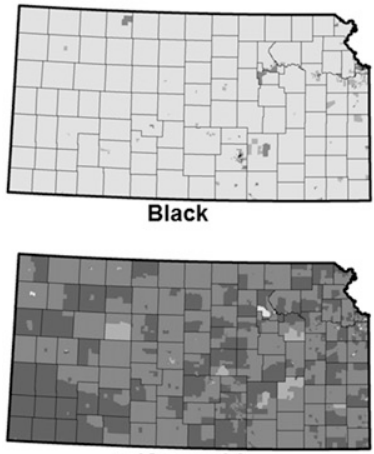

$<18$ yrs old

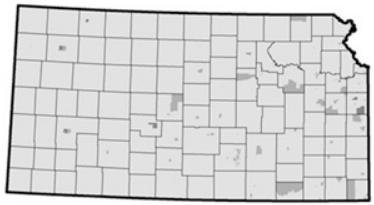

Pub. Asst.

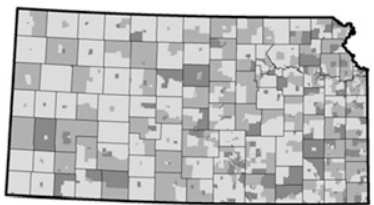

Sing. Fem. head of $\mathrm{HH}$
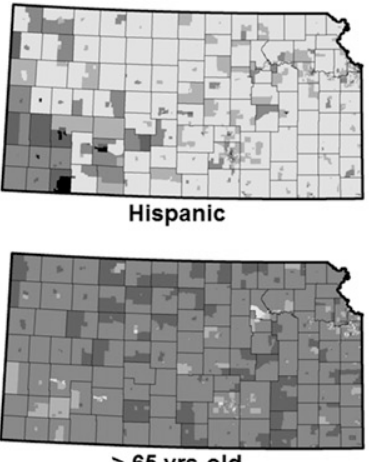

$>65$ yrs old

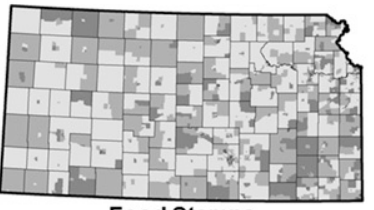

Food Stamps

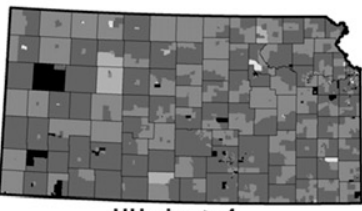

$\mathrm{HH}$ size $>4$

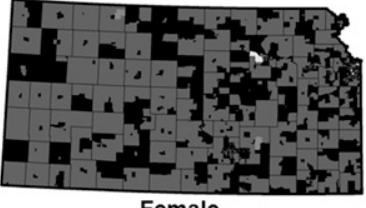

Female

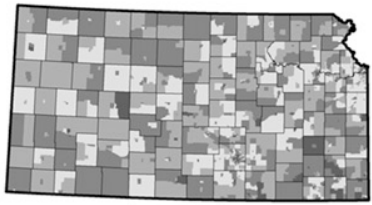

In poverty

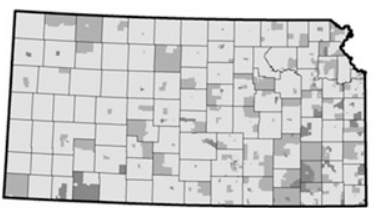

Disability

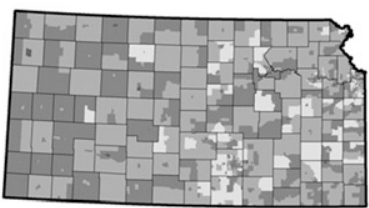

Renters
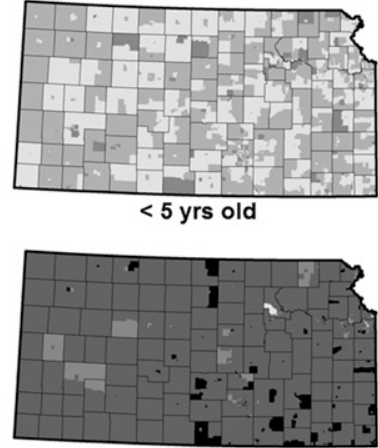

Unemployed

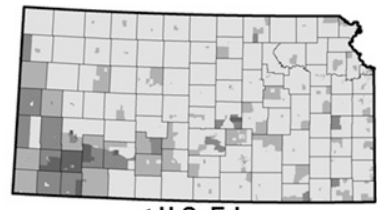

$<$ H.S. Ed.

SEDVI Variables (\%)

0 - 5

$6-10$

$11-25$

$26-50$

$>50$

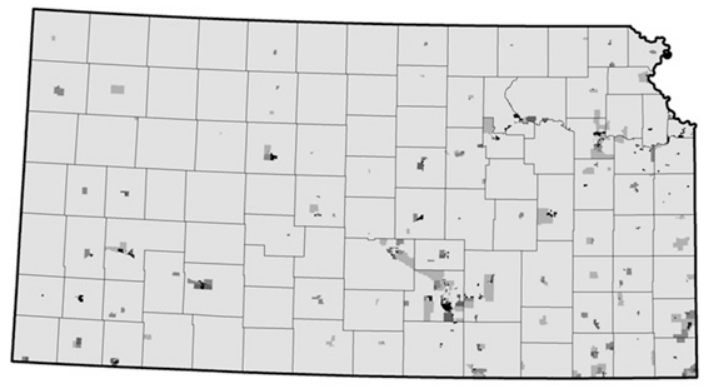

MH per sq. $\mathbf{k m}$

$0.0-1.0$

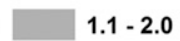

$2.1-4.0$

$4.1-10.0$

$>10.0$
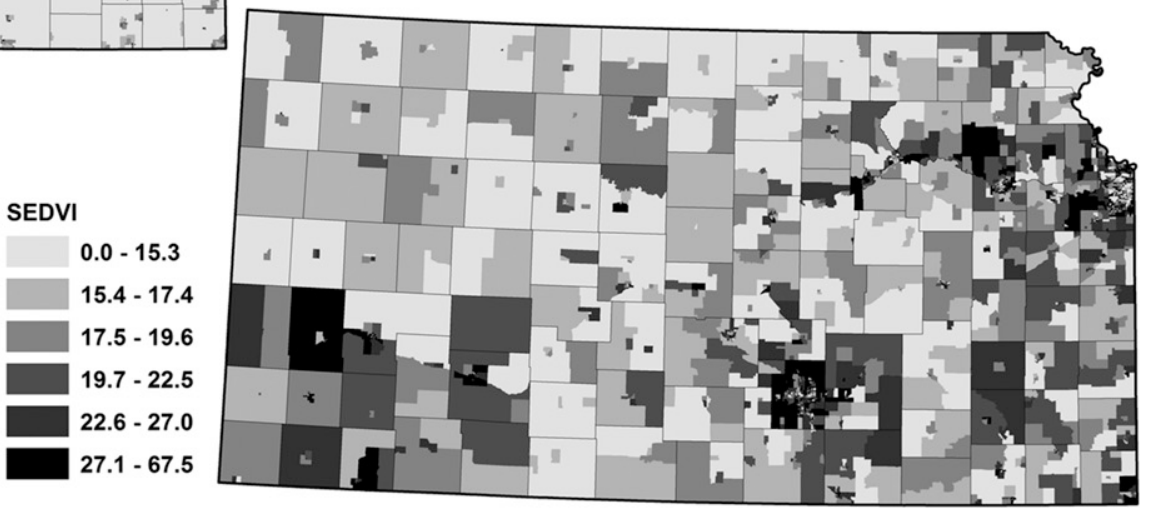

FIG. 6. As in Fig. 5, but for KS.

and socioeconomic and demographically vulnerable factors are linked across geographic space at fine spatial scale in the Southeast. This combination of increased vulnerability with housing stock that is less wind resistant (i.e., MHs) highlights one of the most tornadovulnerable populations in the United States. Thus, some of the most socioeconomically and demographically marginalized populations in the United States are also more susceptible to destruction from tornadoes and other wind hazards.

As illustrated, there are fewer MHs in Kansas located in rural areas, compared to Alabama, and MHs tend to 

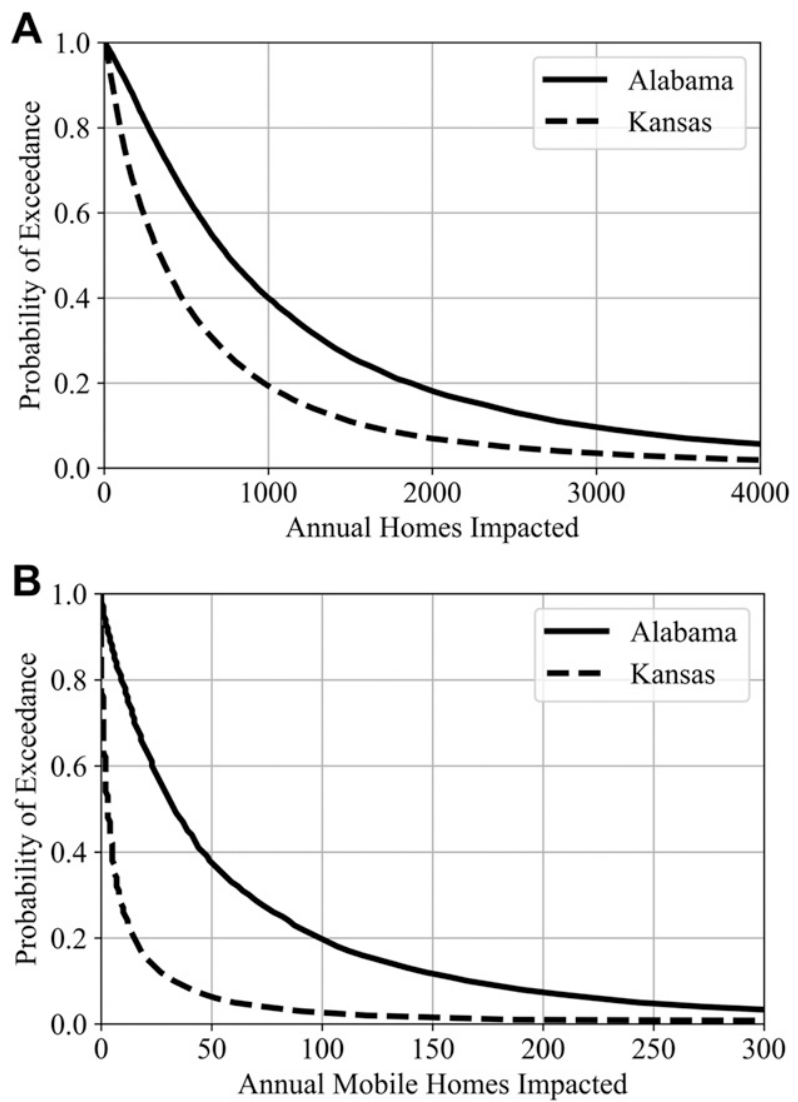

FIG. 7. Annual AL (solid black line) and KS (dashed black line) tornado impact POE curves for (a) HUs and (b) MHs using a $10000-\mathrm{yr}$ $\mathrm{EF} 1+$ tornado footprint simulation.

be located on the fringe of urban centers in suburban land use. Kansas SEDVI metrics illustrate that MHs also coincide with elevated measures of socioeconomic and demographic vulnerability. However, SEDVI values in Kansas are not as concentrated in rural and exurban areas as in Alabama. Rather, elevated SEDVI measures are found more commonly in suburban regions where MHs are also likely to be found. This difference between Alabama and Kansas land use and SEDVI measures is explained by the contrasting development patterns in each state. Because exurban growth and urban sprawl has been limited in Kansas by zoning practices related to the preservation of agriculture and pasture lands, populations and households that are determined to be at greater vulnerability are more likely to fall on peripheries of the urban core in suburban and exurban land use (e.g., southeast Garden City, Kansas).

\section{f. Assessment of tornado impacts on MHs using a Monte Carlo model}

POE curves derived from TorMC Monte Carlo simulations are used to illustrate $\mathrm{HU}$ and $\mathrm{MH}$ tornado
TABLE 5. Annual tornado impact statistics for $\mathrm{HU}$ and MH by 10000 -yr tornado $(\mathrm{EF} 1+)$ tornado simulations.

\begin{tabular}{clcc}
\hline \hline Housing type & \multicolumn{1}{c}{ Impact statistics } & AL & KS \\
\hline \multirow{2}{*}{ HU } & Median & 751 & 341 \\
& Mean & 1298 & 687 \\
& Std dev & 1806 & 1119 \\
& Coefficient of variation & 1.4 & 1.6 \\
& 95th percentile & 4264 & 2445 \\
MH & 99th percentile & 8328 & 5201 \\
& Median & 33 & 3 \\
& Mean & 68 & 14 \\
& Std dev & 103 & 41 \\
& Coefficient of variation & 2.7 & 2.9 \\
& 95th percentile & 243 & 60 \\
& 99th percentile & 513 & 186 \\
\hline
\end{tabular}

impact potential for Alabama and Kansas (Fig. 7). MH impact statistics and probabilities are compared against those for all housing to reveal differences in tornado impact potential between housing types. ${ }^{4}$ Tornado impact statistics and POEs for all HUs in Kansas and Alabama demonstrate that tornado-HU impact potential in Alabama is greater than in Kansas. Specifically, the mean (median) number of HUs affected by tornadoes in a given year in Alabama is $88 \%(120 \%)$ higher in Alabama (Table 5). Alabama's 95th and 99th percentiles of annual HU impacts are $60 \%$ higher than Kansas. It is also $68 \%(150 \%)$ more likely for an EF1+ tornado to damage an HU (100 HUs) in Alabama than in Kansas (Table 6). These elevated Alabama central tendency and percentile tornado-HU impact results are explained by the larger number of HUs in Alabama, the greater total tornado damage area (Ashley and Strader 2016), and a more sprawling suburban, exurban, and relatively high-density rural land use (Table 2).

The expected mean and median annual tornado impacts on MHs in Alabama are 385\% (54 MH per year) and $1000 \%$ (30 MHs per year) higher than in Kansas (Table 5). Tornado-MH impact $95^{\text {th }}$ - and 99 th-percentile values in Alabama are also $305 \%$ and $176 \%$ higher in Alabama. The probability that an $\mathrm{MH}$ is impacted by an EF1+ tornado is $350 \%$ more likely in Alabama (Table 6). However, the likelihood that 100 or more MHs are damaged by an EF1+ tornado is only $13 \%$ higher in Alabama. This finding illustrates the effect that more $\mathrm{MH}$ clustering in Kansas has on tornado-MH impact probability, especially for tornado events that affect many MHs. Because the HU and MH mean impact values for Alabama and Kansas are also vastly different, the coefficient of variation was calculated for

\footnotetext{
${ }^{4} \mathrm{PH}$ impacts were not analyzed in this study because of poor data quality, error correction limitations, and locational accuracy.
} 
TABLE 6. The probability (prob) that an EF1+ tornado damages an $\mathrm{HU}$ or $\mathrm{MH}$ in $\mathrm{AL}$ or $\mathrm{KS}$. $\mathrm{MH}$-tornado impact probability thresholds of greater than 1, 100, 500, and $1000 \mathrm{MHs}$ per EF1+ tornado event occurrence.

\begin{tabular}{|c|c|c|c|c|c|c|c|c|}
\hline \multirow[b]{2}{*}{ State } & \multicolumn{2}{|c|}{$\begin{array}{c}\text { Prob }>1 \\
\text { home }\end{array}$} & \multicolumn{2}{|c|}{$\begin{array}{c}\text { Prob }>100 \\
\text { homes }\end{array}$} & \multicolumn{2}{|c|}{$\begin{array}{c}\text { Prob }>500 \\
\text { homes }\end{array}$} & \multicolumn{2}{|c|}{$\begin{array}{c}\text { Prob }>1000 \\
\text { homes }\end{array}$} \\
\hline & $\mathrm{HU}$ & $\mathrm{MH}$ & $\mathrm{HU}$ & MH & $\mathrm{HU}$ & MH & $\mathrm{HU}$ & MH \\
\hline $\mathrm{AL}$ & 0.69 & 0.18 & 0.10 & 0.0098 & 0.03 & 0.0078 & 0.0114 & 0.0053 \\
\hline $\mathrm{KS}$ & 0.41 & 0.04 & 0.04 & 0.0087 & 0.01 & 0.0034 & 0.0098 & $<0.0001$ \\
\hline
\end{tabular}

each 10000 -yr simulation to best compare the variability in annual expected tornado impacts across states and housing types. Kansas has greater expected annual tornado impact variabilities for both HUs and MHs. This finding supports prior research that indicated tornado impact variability is generally higher across landscapes that have a more clustered development pattern (i.e., Strader et al. 2018). However, comparing the coefficient of variation results for MHs and HUs, MH impact variability is much greater for both Alabama and Kansas. This suggests that when assessing the tornado disaster potential of a region, the spatial clustering of MHs is equally important as the total number of MHs. Because MHs in Kansas are more often found in suburbia and rarely found in rural areas, tornado-MH impacts are much more variable, compared to Alabama. The greater number of MHs in exurban and higher-density rural locations in Alabama lowers tornado impact variability while simultaneously increasing the mean and median tornado impact values.

In general, in Alabama and Kansas, tornado impact probability is controlled by three primary factors: tornado risk, number of homes exposed to the hazard, and spatial distribution of exposed homes. As this study and prior research (e.g., Brooks et al. 2003; Dixon et al. 2011; Ashley and Strader 2016) has illustrated, tornado risk in Alabama and Kansas is similar, with Kansas experiencing a greater number of tornadoes annually and Alabama having a greater overall tornado footprint (i.e., total area of tornado damage) annually. Taking the second and third tornado impact controls into account, there is a balance, or tradeoff, between housing density and the pattern of development as it relates to tornado impact potential and magnitude. For example, given a constant total number of MHs, a more clustered (dispersed or sprawling) development pattern will lead to greater (lesser) tornado impact variability. However, the total number of MHs in Alabama and Kansas is not equal or constant between the two states; Alabama contains a far greater number of MHs. In addition, MHs in Alabama are more often found in exurban areas compared to suburban in Kansas. Alabama MHs are found in both $\mathrm{MH}$ communities/parks (clustered) and isolated areas (dispersed) in exurban and rural areas. The resulting combination of a greater number of $\mathrm{MHs}$ and a more sprawling spatial pattern leads to tornado impact probabilities 4.5 times greater in the Southeast than in the central Plains.

\section{Conclusions}

Disasters are social constructs that occur when hazards, such as tornadoes, interact with society and the accompanying population's vulnerabilities (Quarantelli 1992; Pelling 2003). To understand disaster potential and differences in tornado impacts for $\mathrm{MH}$ residents in the Southeast and central Plains, tornado risk and associated socioeconomic and demographic characteristics must be considered. By integrating $\mathrm{MH}$ locations derived from land-parcel data and socioeconomic and demographic variables from census data, finescale measures of physical and social vulnerability to tornadoes were created for Alabama and Kansas. The combination of these physical, socioeconomic, and demographic vulnerability measures provides a more holistic understanding of tornado impact and disaster potential in the Southeast and central Plains while also highlighting where the most vulnerable populations are located. Whereas prior research has suggested that a primary reason for elevated tornado mortality rates in the Southeast are vulnerability factors such as elevated population density, lower income, and increased minority populations, this study illustrates that physical and social vulnerability are connected to both the magnitude of the vulnerability measure and its spatial distribution across the landscape.

Combining both physical (i.e., MHs) and social (i.e., SEDVI measures) vulnerability analyses, Alabama populations are altogether much more vulnerable to tornadoes compared to those in Kansas. Yet, when examining MH density and populations in Alabama that have been deemed more socially vulnerable by the SEDVI analyses, there is an inverse relationship indicating that more isolated MHs (i.e., not located with an MH community or park) have a tendency to also be more socioeconomically and demographically vulnerable to tornadoes. Altogether, results from this study not only support prior research that suggests populations in rural areas are more socially vulnerable to hazards (e.g., Cutter et al. 2003), but also indicates that many of these populations are disproportionately more physically vulnerable to tornadoes.

Overall, we have illustrated that to understand tornado impacts and mitigate potential consequences, both physical and social components of disaster must be considered. Policy makers, elected officials, and governmental agencies at local, state, and national scales should employ the 
findings herein and conduct similar analyses to better understand where the most vulnerable populations are located so that hazard impact reduction strategies on the short- and long-term time scales may be implemented. Land planners and policy makers should improve and enforce building codes that increase individual and community resilience. For example, MHs located in tornado and other wind hazard-prone regions should be required to have concrete foundations, anchor bolts, and hurricane ties so that they are more resistant to these hazards. Although there are many known issues with community tornado shelters (e.g., Schmidlin et al. 2009), areas where there is a high concentration of the vulnerable housing stock, such as MH parks, should invest in tornado shelters or safe rooms to reduce tornado consequences, lower disaster costs, and potentially save lives (Merrell et al. 2002; Simmons and Sutter 2007; Prevatt et al. 2012). Last, researchers, policy makers, engineers, and members of community integrated warning teams (IWT) should continue to work together to reduce tornado vulnerability and increase survivability during tornado events. The methods and results presented in this study serve to initiate a dialogue among policy makers, IWT members, and the public so that steps can be taken to reduce the effects of future tornado hazards on society, especially for those more vulnerable populations.

Acknowledgments. The authors wish to thank the three anonymous referees for their helpful comments and thorough reviews. We also wish to thank Drs. Kim Klockow-McClain (Cooperative Institute for Mesoscale Meteorological Studies), Kevin Ash (University of Florida), David Roueche (Auburn University), and Michael Egnoto (Walter Reed Army Institute of Research) for assisting on work leading up to this research. This research was supported by the National Oceanic and Atmospheric Administration (NOAA) Verifications of the Origins of Rotation Experiment in the Southeast (VORTEX-SE) Grant NA17OAR4590191.

\section{REFERENCES}

Agee, E., and S. Childs, 2014: Adjustments in tornado counts, F-scale intensity, and path width for assessing significant tornado destruction. J. Appl. Meteor. Climatol., 53, 1494-1505, https://doi.org/10.1175/JAMC-D-13-0235.1.

Ash, K. D., 2017: A qualitative study of mobile home resident perspectives on tornadoes and tornado protective actions in South Carolina, USA. GeoJournal, 82, 533-552, https://doi.org/ 10.1007/s10708-016-9700-8.

Ashley, W. S., 2007: Spatial and temporal analysis of tornado fatalities in the United States: 1880-2005. Wea. Forecasting, 22, 1214-1228, https://doi.org/10.1175/2007WAF2007004.1.

— dynamic ingredients of risk and exposure are changing the tornado disaster landscape. Bull. Amer. Meteor. Soc., 97, 767786, https://doi.org/10.1175/BAMS-D-15-00150.1.

— A. Krmenec, and R. Schwantes, 2008: Vulnerability due to nocturnal tornadoes. Wea. Forecasting, 23, 795-807, https:// doi.org/10.1175/2008WAF2222132.1.

— S. Strader, T. Rosencrants, and A. Krmenec, 2014: Spatiotemporal changes in tornado hazard exposure: The case of the expanding bull's-eye effect in Chicago, Illinois. Wea. Climate Soc., 6, 175-193, https://doi.org/10.1175/WCAS-D-13-00047.1.

Baker, E. H., 2014: Socioeconomic status, definition. The Wiley Blackwell Encyclopedia of Health, Illness, Behavior, and Society, W. C. Cockerham, R. Dingwall, and S. Quah, Eds., John Wiley and Sons, 2210-2214, https://doi.org/10.1002/ 9781118410868.wbehibs395.

Boruff, B. J., J. A. Easoz, S. D. Jones, H. R. Landry, J. D. Mitchem, and S. L. Cutter, 2003: Tornado hazards in the United States. Climate Res., 24, 103-117, https://doi.org/ 10.3354/cr024103.

Brooks, H. E., and C. A. Doswell III, 2002: Deaths in the 3 May 1999 Oklahoma City tornado from a historical perspective. Wea. Forecasting, 17, 354-361, https://doi.org/10.1175/15200434(2002)017<0354:DITMOC > 2.0.CO;2.

,-- , and M. Kay, 2003: Climatological estimates of local daily tornado probability for the United States. Wea. Forecasting, 18, 626-640, https://doi.org/10.1175/1520-0434(2003) 018<0626:CEOLDT > 2.0.CO;2.

_ G. Carbin, and P. Marsh, 2014: Increased variability of tornado occurrence in the United States. Science, 346, 349-352, https://doi.org/10.1126/science.1257460.

Brown, D., K. Johnson, T. Loveland, and D. Theobald, 2005: Rural land-use trends in the conterminous United States, 1950-2000. Ecol. Appl., 15, 1851-1863, https://doi.org/ 10.1890/03-5220.

Chaney, P. L., and G. S. Weaver, 2010: The vulnerability of mobile home residents in tornado disasters: The 2008 Super Tuesday tornado in Macon County, Tennessee. Wea. Climate Soc., 2, 190-199, https://doi.org/10.1175/2010WCAS1042.1.

Cutter, S. L., 2012: Hazards, Vulnerability and Environmental Justice. Routledge, 448 pp.

— B. J. Boruff, and W. L. Shirley, 2003: Social vulnerability to environmental hazards. Soc. Sci. Quart., 84, 242-261, https:// doi.org/10.1111/1540-6237.8402002.

_ _ C. T. Emrich, J. T. Mitchell, B. J. Boruff, M. Gall, M. C. Schmidtlein, C. G. Burton, and G. Melton, 2006: The long road home: Race, class, and recovery from Hurricane Katrina. Environment, 48, 8-20, https://doi.org/10.3200/ ENVT.48.2.8-20.

— C. Emrich, J. Webb, and D. Morath, 2009: Social vulnerability to climate variability hazards: A review of the literature. HVRI Final Rep. to Oxfam America, 44 pp.

Daneshvaran, S., and R. Morden, 2007: Tornado risk analysis in the United States. J. Risk Finance, 8, 97-111, https://doi.org/ 10.1108/15265940710732314.

Dixon, P. G., and A. E. Mercer, 2012: Reply to "Comments on 'Tornado risk analysis: Is Dixie Alley an extension of Tornado Alley?"' Bull. Amer. Meteor. Soc., 93, 408-410, https://doi.org/ 10.1175/BAMS-D-11-00219.1.

,$- \ldots$, J. Choi, and J. S. Allen, 2011: Tornado risk analysis: Is Dixie Alley an extension of Tornado Alley? Bull. Amer. Meteor. Soc., 92, 433-441, https://doi.org/10.1175/2010BAMS3102.1.

Dixon, P. M., 2002: Ripley's $K$ function. Encyclopedia of Environmetrics, W. Piegorsch and A. H. El-Shaarawi, Eds., Wiley, 1796-1803. 
Dixon, R. W., and T. W. Moore, 2012: Tornado vulnerability in Texas. Wea. Climate Soc., 4, 59-68, https://doi.org/10.1175/ WCAS-D-11-00004.1.

Doswell, C. A., III, 2007: Small sample size and data quality issues illustrated using tornado occurrence data. Electron. J. Severe Storms Meteor., 2 (5), 1-16.

Duany, A., E. Plater-Zyberk, and J. Speck, 2000: Suburban Nation: The Rise of Sprawl and the Decline of the American Dream. North Point Press, 320 pp.

Elder, K., S. Xirasagar, N. Miller, S. A. Bowen, S. Glover, and C. Piper, 2007: African Americans' decisions not to evacuate New Orleans before Hurricane Katrina: A qualitative study. Amer. J. Public Health, 97, 2112-2222, https://doi.org/ 10.2105\%2FAJPH.2006.100867e.

Emrich, C. T., and S. L. Cutter, 2011: Social vulnerability to climatesensitive hazards in the southern United States. Wea. Climate Soc., 3, 193-208, https://doi.org/10.1175/2011WCAS1092.1.

Enarson, E., A. Fothergill, and L. Peek, 2007: Gender and disaster: Foundations and directions. Handbook of Disaster Research, Springer, 130-146.

Flanagan, B. E., E. W. Gregory, E. J. Hallisey, J. L. Heitgerd, and B. Lewis, 2011: A social vulnerability index for disaster management. J. Homeland Secur. Emerg. Manage., 8, 3, https:// doi.org/10.2202/1547-7355.1792.

Fothergill, A., and L. Peek, 2004: Poverty and disasters in the United States: A review of recent sociological findings. Nat. Hazards, 32, 89-110, https://doi.org/10.1023/B:NHAZ.0000026792.76181.d9.

Gagan, J., A. Gerard, and J. Gordon, 2010: A historical and statistical comparison of "Tornado Alley" to "Dixie Alley." Natl. Wea. Dig., 34, 145-155.

Gillham, O., 2002: The Limitless City: A Primer on the Urban Sprawl Debate. Island Press, 328 pp.

Greene, R. P., and J. B. Pick, 2011: Exploring the Urban Community: A GIS Approach. Pearson Higher Ed, 432 pp.

Gryn, T., 2016: The foreign-born by urban-rural status of counties: 2011-2015. United States Census Bureau, https://www.census.gov/ newsroom/blogs/random-samplings/2016/12/the_foreign-bornby.html.

Kansas Department of Agriculture, 2016: Kansas Agriculture. Kansas Department of Agriculture, http://agriculture.ks.gov/ about-kda/kansas-agriculture.

Kim, S., 1999: Urban development in the United States, 1690-1990. National Bureau of Economic Research Working Paper 7120, 46 pp., http://www.nber.org/papers/w7120.pdf.

Kulcsàr, L. J., 2007: Baby boomers and immigrants on the range: Population trends in Kansas. Kansas Policy Rev., 29 (1), 1-24, http://www.ipsr.ku.edu/publicat/kpr/kprV29N1/kprv29n1.pdf.

Lang, R., 2003: Edgeless Cities: Exploring the Elusive Metropolis. Brookings Institution Press, 154 pp.

Masozera, M., M. Bailey, and C. Kerchner, 2007: Distribution of impacts of natural disasters across income groups: A case study of New Orleans. Ecol. Econ., 63, 299-306, https://doi.org/10.1016/ j.ecolecon.2006.06.013.

McGuire, L., E. Ford, and C. Okoro, 2007: Natural disasters and older US adults with disabilities: Implications for evacuation. Disasters, 31, 49-56, https://doi.org/10.1111/j.1467-7717.2007.00339.x.

Merrell, D., K. Simmons, and D. Sutter, 2002: Taking shelter: Estimating the safety benefits of tornado safe rooms. Wea. Forecasting, 17, 619-625, https://doi.org/10.1175/1520-0434(2002) $017<0619$ :TSETSB $>2.0 . \mathrm{CO} ; 2$.

Meyer, C., H. Brooks, and M. Kay, 2002: A hazard model for tornado occurrence in the United States. Preprints, 16th Conf. on Probability and Statistics in the Atmospheric Sciences/13th Symp. on Global Change and Climate Variations, Orlando,
FL, Amer. Meteor. Soc., J3.6, https://ams.confex.com/ams/ annual2002/techprogram/paper_27595.htm.

Mitchell, P. I., I. Scott, and P. R. Evans, 2000: Vulnerability to severe weather and regulation of body mass of Icelandic and British Redshank Tringa totanus. J. Avian Biol., 31, 511-521, https://doi.org/10.1034/j.1600-048X.2000.1310411.x.

Mooney, C., 1997: Monte Carlo Simulation. Sage Publications, $103 \mathrm{pp}$.

Morrill, R. L., 1990: Regional demographic structure of the United States. Prof. Geogr., 42, 38-53, https://doi.org/10.1111/j.00330124.1990.00038.x.

Morrow, B. H., 1999: Identifying and mapping community vulnerability. Disasters, 23, 1-18, https://doi.org/10.1111/14677717.00102 .

, 2008: Community resilience: A social justice perspective. The Community and Regional Resilience Initiative Research Rep. 4, 31 pp.

Morss, R., O. Wilhelmi, G. A. Meehl, and L. Dilling, 2011: Improving societal outcomes of extreme weather in a changing climate: An integrated perspective. Annu. Rev. Environ. Resour., 36, 1-25, https://doi.org/10.1146/annurev-environ-060809-100145.

NOAA/NCEI, 2018: Billion-dollar weather and climate disasters: Overview. NOAA/NCEI, accessed 1 March 2018, https:// www.ncdc.noaa.gov/billions/.

Peacock, W. G., B. H. Morrow, and H. Gladwin, Eds., 1997: Hurricane Andrew: Ethnicity, Gender, and the Sociology of Disasters. Routledge, $277 \mathrm{pp}$.

Peguero, A. A., 2006: Latino disaster vulnerability: The dissemination of hurricane mitigation information among Florida's homeowners. Hisp. J. Behav. Sci., 28, 5-22, https://doi.org/ 10.1177/0739986305284012.

Pelling, M., 2003: The Vulnerability of Cities: Natural Disasters and Social Resilience. Routledge, $212 \mathrm{pp}$.

Phillips, B. D., and P. L. Hewett, 2005: Home alone: Disasters, mass emergencies, and children in self-care. J. Emerg. Manage., 3 (2), 31-35.

Prevatt, D. O., and Coauthors, 2012: Making the case for improved structural design: Tornado outbreaks of 2011. Leadership Manage. Eng., 12, 254-270, https://doi.org/10.1061/(ASCE) LM.1943-5630.0000192.

Quarantelli, E. L., 1992: Urban vulnerability and technological hazards in developing societies. Environmental Management and Urban Vulnerability, A. Kreimer and M. Munasinghe, Eds., World Bank, 187-236.

Schmidlin, T. W., B. O. Hammer, Y. Ono, and P. S. King, 2009: Tornado shelter-seeking behavior and tornado shelter options among mobile home residents in the United States. Nat. Hazards, 48, 191-201, https://doi.org/10.1007/s11069-008-9257-z.

Simmons, K. M., and D. Sutter, 2007: Tornado shelters and the housing market. Construct. Manage. Econ., 25, 1119-1126, https://doi.org/10.1080/01446190701618299.

— and - 2008: Manufactured home building regulations and the February 2, 2007 Florida tornadoes. Nat. Hazards, 46, 415425, https://doi.org/10.1007/s11069-007-9192-4.

—, and - 2011: Economic and Societal Impacts of Tornadoes. Amer. Meteor. Soc., 282 pp.

Smith, S., M. J. Tremethick, P. Johnson, and J. Gorski, 2009: Disaster planning and response: Considering the needs of the frail elderly. Int. J. Emerg. Manage., 6 (1), 1-13, https://doi.org/ 10.1504/IJEM.2009.025170.

Strader, S. M., and W. S. Ashley, 2015: The expanding bull's-eye effect. Weatherwise, 68, 23-29, https://doi.org/10.1080/ 00431672.2015 .1067108 
_ T. J. Pingel, and W. S. Ashley, 2016: A Monte Carlo model for estimating tornado impacts. Meteor. Appl., 23, 269-281, https://doi.org/10.1002/met.1552.

, W. S. Ashley, T. J. Pingel, and A. J. Krmenec, 2017a: Observed and projected changes in United States tornado exposure. Wea. Climate Soc., 9, 109-123, https://doi.org/ 10.1175/WCAS-D-16-0041.1.

— — — — - and ——, 2017b: Projected 21st century changes in tornado exposure, risk, and disaster potential. Climatic Change, 141, 301-313, https://doi.org/10.1007/s10584017-1905-4.

,,--- , and -2018 : How land use alters the tornado disaster landscape. Appl. Geogr., 94, 18-29, https://doi.org/ 10.1016/j.apgeog.2018.03.005.

Sutter, D., and K. M. Simmons, 2010: Tornado fatalities and mobile homes in the United States. Nat. Hazards, 53, 125-137, https:// doi.org/10.1007/s11069-009-9416-x.
Theobald, D. M., 2005: Landscape patterns of exurban growth in the USA from 1980 to 2020. Ecol. Soc., 10, 32, https://doi.org/ 10.5751/ES-01390-100132.

Trujillo-Pagan, N., 2007: Katrina's Latinos: Vulnerability and disasters in relief and recovery. Through the Eye of Katrina: Social Justice in the United States, Academic Press, 147-168.

USDA, 2017: Major land uses. United States Department of Agriculture, https://www.ers.usda.gov/data-products/major-land-uses/.

Verbout, S., H. Brooks, L. Leslie, and D. Schultz, 2006: Evolution of the U.S. tornado database: 1954-2003. Wea. Forecasting, 21, 86-93, https://doi.org/10.1175/WAF910.1.

Whyte, W. H., 2013: The Organization Man. University of Pennsylvania Press, 448 pp.

Wurman, J., C. Alexander, P. Robinson, and Y. Richardson, 2007: Low-level winds in tornadoes and potential catastrophic tornado impacts in urban areas. Bull. Amer. Meteor. Soc., 88, 31-46, https://doi.org/10.1175/BAMS-88-1-31. 